DOI 10.32726/2411-3417-2019-4-45-55

удК 327; 339

\title{
Станислав Митрахович
}

\section{«Газовый треугольник» РФ-ЕС-Украина: в ожидании рисков}

Аннотация. Подготовка к заключению нового транзитного газового контракта между Россией и Украиной в конце 2019 г. оказалась крайне сложным политико-экономическим процессом, затрагивающим интересы различных игроков. Столкнулись интересы и позиции российского и украинского политического руководства, бизнес-компаний обеих стран, a также США, ЕС, Германии. Важным политическим контекстом энергетической дипломатии в связи с подготовкой нового контракта стала интеграционная политика $E C$, в том числе по имплементации норм обновленной Газовой директивы ЕС в право государств Союза.

Ключевые слова: газопроводы, газопроводная политика, Европейский союз, российско-европейские отношения, российско-украинские отношения, российско-украинский контракт на транзит газа.

$\Pi_{\text {a }}$

роблема обходных (то есть обходящих Украину) газопроводов в Европу возникла в результате постепенного ухудшения российско-украинских отношений в газовой сфере (как минимум, с момента перекрытия газового транзита в 2006 г.). Желание России сократить зависимость от Украины в газовых вопросах во многом стало реакцией на стратегические планы самой Украины отдалиться от Москвы, а также на попытки Киева после «оранжевой революции» активизировать свое участие в евроинтеграции в пику российскому видению оптимальных отношений на постсоветском пространстве. Евромайдан 2014 г. лишь усилил давно вызревавшие тренды.

Конец осени 2019 г. был для Газпрома достаточно удачным с точки зрения продвижения обходных газопроводов в Европу. Уже есть разрешение Дании на строительство «Северного потока - 2» (СП-2) в ее исключительной экономической зоне. Появилось еще и решение немецкого парламента (бундестага) принять поправки к внутреннему законодательству ФРГ относительно национальной имплементации обновленной Газовой директивы ЕС.

Решение бундестаг принял со второй попытки - поначалу мешали определенные разногласия в германской элите по вопросу СП-2. Однако фундаментальный фактор заинтересованности большинства политического и экономического класса ФРГ в этом проекте взял верх, и поправки были одобрены.

Сведения об авторе: МИТРАХОВИЧ Станислав Павлович - ведущий эксперт Фонда национальной энергетической безопасности, старший преподаватель, старший научный сотрудник Финансового университета при правительстве PФ; stasmitr@mail.ru. 
Политико-юридический смысл происшедшего в том, что партнеры СП-2 добились в Германии принятия закона, выводящего газопровод из-под регулирования Третьего энергопакета (Газовой директивы) по упрощенной схеме. Принятая весной 2019 г. Газовая директива на уровне ЕС подразумевает, что приходящие в страны ЕС морские газопроводы должны соответствовать требованиям о разделении видов деятельности по поставке и транспортировке газа, а также по доступу третьих лиц. Из буквального прочтения данной директивы следует, что Nord Stream 2 AG, владелец и оператор СП-2, не может загружать газопровод полностью только своим газом. Но обновленная Газовая директива позволяет национальному государству в порядке исключения выводить газопровод, приходящий извне ЕС, из-под антимонопольных требований. Причем подобное исключение допускается как по упрощенной, так и по сложной схеме.

Германии удалось пробить такую форму имплементации Газовой директивы ЕС в свое национальное законодательство, которая в теории позволит вывести СП-2 изпод регулирования по упрощенной схеме. Будет считаться, что это «старый» газопровод, в него уже вложены деньги (хоть он еще и не закончен), а потому он и не должен регулироваться обновленной Газовой директивой. Формальной датой, отделяющей «старые» газопроводы от «новых», в Газовой директиве считается 23 мая 2019 г.

Германии придется согласовывать свое решение с Европейской комиссией. Таков был компромисс, достигнутый в рамках реформы Газовой директивы ЕС весной 2019 г. Точнее, Еврокомиссия может именно так трактовать этот момент, потребовав у Германии согласования. Ведь Третий энергетический пакет изначально был очень политизированным и инструментальным [Европейская интеграция...]. Кроме того, это та часть европейского права, которая совсем молода, в которой нет опыта применения и его интерпретации на практике. Соответственно, у еврократов может возникнуть желание инструментально и именно «под себя» трактовать энергетическое право ЕС. Польша уже пообещала, что будет «отстаивать применение Германией норм ЕС применительно к СП-2». На практике этот процесс может выражаться в столкновениях внутри институтов ЕС (в Совете ЕС, Еврокомиссии, в Суде ЕС и т. д.).

Поскольку объективно роль Германии в Евросоюзе куда выше, чем роль Польши, да и частью еврократов являются как раз ставленники Берлина, то велика вероятность, что в итоге Еврокомиссия утвердит немецкое прочтение Газовой директивы. Тем более что остаются и иные способы обойти антимонопольное регулирование и организовать полную загрузку Северного потока - 2.

Во-первых, Германия могла бы пойти на более сложную схему выведения СП-2 изпод действия Газовой директивы - апеллируя не ко времени реализации проекта («старый» он или «новый»), а пользуясь своим национальным правом на предоставление разрешения. Весьма вероятно, что подобный подход потребовал бы пересмотра схемы владения и организации работы СП-2. Например, можно выделить для управления 12-мильным участком трубопровода в территориальных водах ФРГ отдельную компанию, где Газпром формально не будет контролирующим акционером. Кстати, 
такая компания, по сообщениям немецкой газеты Handelsblatt, предварительно уже была создана, но пока как «пустышка», без передачи ей активов.

Во-вторых, сам Газпром мог бы договариваться со своими партнерами о переносе точек выдачи газа. Вариантов много: например, продажа газа на территории России, на виртуальном хабе в Балтийском море, на входе в Германию у Грайфсвальда. Подобные шаги тоже потребовали бы согласования, возможно, даже отстаивания их в судебном порядке, но при поддержке ФРГ схема скорее всего сработала бы. Поэтому принятое в ноябре 2019 г. решение бундестага по имплементации Газовой директивы, хотя оно и облегчает задачу для Газпрома и СП-2, не было абсолютно необходимым, а его отсутствие само по себе не остановило бы проект и не оставило бы трубу на долгие годы полупустой.

В-третьих, можно было бы попытаться оспорить само введение в право стран ЕС обновленной Газовой директивы применительно к СП-2. Nord Stream 2 AG уже успела подать в Суд ЕС на Еврокомиссию и в арбитраж ad hoc на ЕС (это два разных иска) с целью получить исключения для СП-2 и добиться отмены части поправок к Газовой директиве. Но конкретно эти юридические механизмы вряд ли помогут инициированному Россией газовому проекту - Комиссия не допустит столь очевидной «потери лица». Тем более что Nord Stream 2 AG ссылается в арбитраже на Энергетическую хартию, которую признает Швейцария, где зарегистрирована швейцарская дочка Газпрома, но не признает сама Россия; поэтому ссылка не выглядит убедительной.

Позитивной новостью для Газпрома стали официальные сообщения об окончании строительства первой нити газопровода Eugal (продолжения СП-2 в Германии) и начале заполнения ее газом в ходе подготовки к пусконаладочным работам. Впрочем, вторая нитка Eugal будет построена лишь к концу 2020 г. - ускорения работ на этом направлении пока нет. Это значит, что при всем желании СП-2 в 2020 г. никак не сможет работать на полную мощность, даже если Германия приложит все усилия для разрешения политико-правовых проблем.

Тем не менее бои в институтах ЕС еще продолжатся. Польша не только фактически пригрозила Германии судами, но и уже оштрафовала одного из кредиторов СП-2, французскую Engie, примерно на 40 млн евро - за якобы имевший место отказ французской компании предоставить подробную информацию о своем участии в проекте СП-2 (данные о распределении, транспортировке, продаже, поставках и хранении газа). Engie пообещала оспорить решение польского антимонопольного регулятора UOKiK в суде. Согласно нормам европейского права, штраф за нарушение антимонопольного законодательства может достигать 10\% от годового оборота компании. В 2018 г. выручка Engie составила 60,6 млрд евро', так что теоретически поляки могут наложить и более крупные штрафы на этого и других участников проекта СП-2. Другое дело, как отреагируют пострадавшие компании и их «материнские» страны. Поднятие ставок в игре

1 Польша оштрафовала партнера Газпрома по «Северному потоку - 2» // https://www.vedomosti. ru/business/articles/2019/11/08/815789-severnomu-potoku-2 
выше определенного уровня создает риски и для самой Польши - особенно когда решается вопрос об окончании практики субсидирования из средств ЕС программ развития стран, присоединившихся к ЕС в ходе его расширения на восток: есть версия, что субсидирование может продолжиться в новой форме, но оно может и прекратиться.

Показательно решение Польши оштрафовать в качестве «демонстративной жертвы» именно Engie. Эта компания всегда была «слабым звеном» в проекте «Северный поток -2», больше всех опасалась санкций и даже неоднократно заявляла публично, что выйдет из проекта, если против него будут введены санкции США. С одной стороны, удар по столь «покладистой» и «послушной» компании можно считать особенно несправедливым. С другой стороны, как раз имидж «слишком осторожной» компании (в сравнении с немцами или австрийцами), возможно, и сыграл с французами дурную шутку. Но и Варшава в ситуации с Engie рискует, учитывая виды французского президента Э. Макрона на лидерство в Евросоюзе после скорого ухода А. Меркель не просто с поста немецкого канцлера, но и с неформального трона «главного политика ЕС».

Если противники СП-2 уже окончательно смирились с тем, что газопровод будет построен, и перешли от борьбы с его строительством к борьбе с его заполнением газом, то на южном маршруте вопросы прокладки новых газопроводов, ведущих из России в Европу, все еще не решены. Труба через Болгарию до Сербии, которая должна прокачивать газ из второй нитки «Турецкого потока», будет готова в лучшем случае лишь летом 2020 г. Общая зависимость Болгарии от «советов» из Вашингтона сохраняется, это давняя особенность политики Софии. Риски здесь не исключены, достаточно вспомнить судьбу проекта «Южный поток», связанную с решением в том числе именно Болгарии. Эта страна в силу давления со стороны Вашингтона и части Евробюрократии (Болгарии указали, что она может потерять сельскохозяйственные субсидии ЕС) отказалась согласовывать строительство своей части «Южного потока», в итоге заблокировав весь проект [Митрахович]. Хотя сам «Турецкий поток», согласно заявлению Р.Т. Эрдогана, будет запущен 8 января 2020 г.

Южный маршрут сейчас даже важнее для РФ, чем северный, поскольку точные сроки запуска первой нитки «Турецкого потока» оказались конкретным аргументом в переговорах с Украиной относительно нового контракта по транзиту российского газа. Успехи же в продвижении СП-2 дают психологическое преимущество российским переговорщикам и важны с точки зрения обсуждения вопросов транзита со второй половины 2020 г. На самые тяжелые, с точки зрения рисков прерывания транзита, первые месяцы 2020 г. (в зимние месяцы самое большое потребление газа) СП-2, в отличие от «Турецкого потока», никак не влияет.

«Турецкий поток» нужен России и для снабжения - в случае прерывания украинского транзита - такой проблемной страны, как Молдавия. Приднестровье официальная Москва пока считает частью Молдавии, а его снабжение газом всегда было политическим приоритетом России - настолько серьезным, что Приднестровье получает газ, не платя за него. С ноября 2019 г. и сама Молдавия приобрела имидж дружественного России государства, за снабжение которого газом необходимо брать на себя особую 
ответственность. Ведь новым премьером Молдавии стал Ион Кику, ставленник условно пророссийского президента Игоря Додона. Подобный расклад может оказаться временным, к власти в Кишиневе могут вновь прийти сторонники приоритетной евроинтеграции, но сейчас позволить замерзнуть Молдавии, которая только-только «развернулась в сторону России», было бы очень нецелесообразно с политической точки зрения.

Снабжать газом «большую Молдавию» теоретически можно и через Румынию. Трансбалканский газопровод пересекает Молдавию и Румынию. Считается, что при его запуске в реверсном режиме газ из «Турецкого потока» мог бы доставляться в Румынию и далее в Молдавию. Но мощностей Трансбалканского газопровода может оказаться недостаточно, для надежности желательно достроить дополнительную инфраструктуру: трубу Яссы - Унгены — Кишинев (Ясско-Унгенский сегмент уже построен).

В любом случае «молдавский кейс» придает дополнительную важность стабильной и полноценной работе «Турецкого потока» (или хотя бы его первой нитки) с января 2020 г.

Риски здесь связаны не только с реальным уровнем готовности инфраструктуры, которая может преувеличиваться турками и болгарами. Есть и сугубо политические риски, обусловленные амбициями Р. Эрдогана, который, понимая, насколько наличие работающих альтернатив украинскому транзиту сейчас важно для Москвы, может попытаться шантажировать Россию. Хотя формально «Турецкий поток» защищен и контрактом, и межправительственным соглашением, на деле Эрдоган в обмен на своевременный запуск и стабильную эксплуатацию «Турецкого потока» (в острый период гипотетических проблем с украинским транзитом) может потребовать от Москвы самых разных шагов - от уступок по Сирии до скидок на газ для турецких потребителей. Не следует также терять из виду, что в ноябре 2019 г. Р. Эрдоган посетил США по приглашению Д. Трампа, который пообещал ему большие экономические и торговые преференции в обмен на отказ от закупок российских ракетных систем C-400. Турецкий лидер на уступки Трампу не пошел, но его характер таков, что он еще может все переиграть, и в любом случае тактика с повышением ставок ему не чужда. (Вспомним хотя бы историю С «внезапным» уничтожением турецкими истребителями российского военного самолета в Сирии в 2015 г.)

К настоящему моменту (на конец 2019 г.) состоялось несколько раундов технических консультаций и собственно переговоров по газу, в том числе на политическом уровне (этот сюжет комментировал лично В. Зеленский после Нормандского саммита в Париже в декабре 2019 г.). Стороны объявили, что согласовали базовые принципы нового контракта; его технико-экономические параметры станут известны, возможно, в 2020 г.

До встречи В. Путина с В. Зеленским 9 декабря 2019 г. в Париже переговаривающиеся стороны лишь нагнетали взаимное давление, пытаясь одержать победу в «игре в труса» (game of chicken). Россия жестко настаивала на отказе Украины от исков в Стокгольмском арбитраже, включая и новые, и уже выигранный иск в 2018 г. Украина заявляла о своей полной готовности к остановке транзита, уверяя, что Газпром пострадает 


\section{Трансбалканский газопровод}

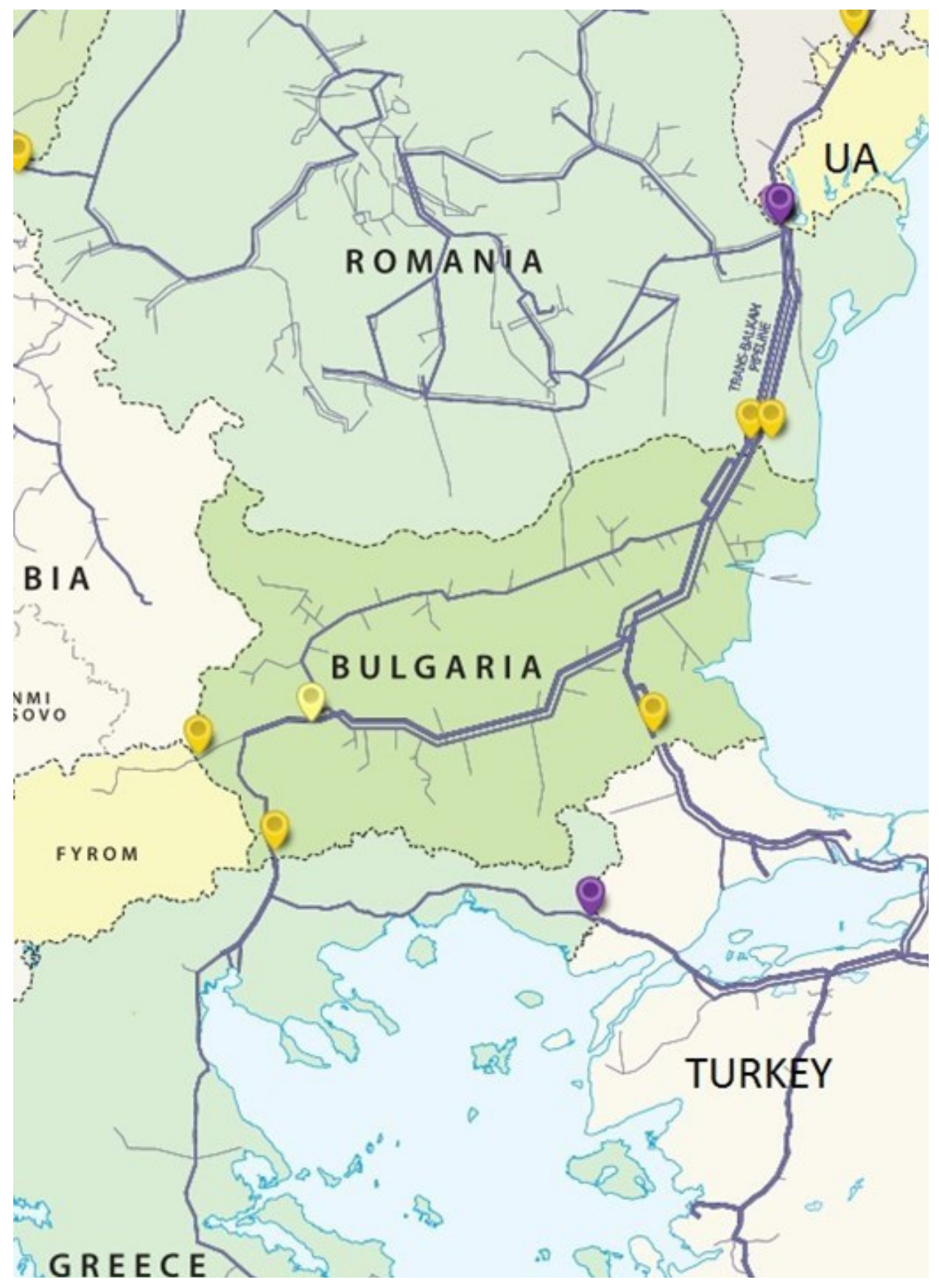

Источник: nalin.ru

больше, а заодно грозила все новыми арестами собственности российского концерна в иностранных юрисдикциях. Очередная новость из этой серии пришла из Латвии, где «Нафтогаз» подал ходатайство в местный суд об аресте неких (неназванных) активов Газпрома во исполнение решений Стокгольмского арбитража. Теоретически арестовывать можно самые разные активы: доли в компаниях, акции, газ в хранилищах и/или газотранспортных системах, банковские счета и пр.

«Задиристости» Украине добавило решение шведского суда в округе Света об отказе в апелляции (официальное название - «обжалование процедуры и принципов выне- 
сенного Стокгольмским арбитражем решения»), которую подавал Газпром. Российская компания считала, что решение Стокгольмского арбитража было диспаритетным: российская сторона, в логике арбитражного решения, была обязана выполнять условие «качай или плати», то есть обязательно загружать украинскую ГТС, а украинская сторона не была обязана выполнять условия «бери или плати», то есть обязательно либо отбирать, либо оплачивать оговоренный в контракте объем газа. В итоге Стокгольмский арбитраж присудил Украине в начале 2018 г. 2,6 млрд долларов. Украинскую сторону данный успех подтолкнул идти и в латвийские суды с требованием арестов активов Газпрома. Причем Украина пообещала в скором будущем дальнейшие аресты активов Газпрома, вплоть до «Турецкого потока».

В реальности навредить Газпрому через арест активов сложно. Во-первых, в 2019 г. была отклонена апелляция Газпрома лишь по недоплате Украиной за газ в конце 2013 - начале 2014 г., а решение по собственно транзитному кейсу ожидается осенью 2020 г. Во-вторых, уже принятые решения об арестах в разных странах только ограничивают право Газпрома продать свое имущество новым владельцам, чего российская компания и так делать не собирается.

Но все же чаша весов в европейских судах явно клонится в сторону Украины. Скорее всего, через год Газпром получит окончательный отказ в своих попытках обжаловать решение Стокгольмского арбитража. И тогда на 100\% исключить аресты важных активов, способные создать реальные проблемы для бизнеса, нельзя. Кроме того, идет пеня за отказ Газпрома платить вовремя (конкретный срок выплаты арбитраж не установил, теоретически ждать можно бесконечно, - точнее, пока все же не начнутся болезненные аресты собственности).

Газпром явно ждал пакетного решения, которое могло бы быть достигнуто на переговорах Путина с Зеленским, либо уступок со стороны Киева, если их сумеет выбить российская сторона. Есть надежда затянуть вопрос с долгами Газпрома и обменять (или как-то взаимозачесть) их с учетом украинского долга в 3 млрд долларов, которые взяло еще правительство Н. Азарова перед Майданом. Судебные разбирательства по этому долгу, который официальный Киев называет «долгом Януковича» и погашать отказывается, продолжаются в британских судах, их исход непредсказуем. Еще вариант - затягивать выплаты до разрешения вопроса о поставках газа на Украину и долг (либо его часть) отдать газом (это тот редкий случай, когда «Нафтогаз» заявил о потенциальной приемлемости компенсации долга газом). Если же Газпром выплатит долг, не дожидаясь окончания всех процедур оспаривания решения Стокгольмского арбитража, то в обмен Россия может потребовать послабления по правилу «качай или плати» в будущем транзитном контракте.

Между тем «Нафтогаз» обещает не только интенсифицировать попытки арестов активов Газпрома. Юрий Витренко, заместитель руководителя «Нафтогаза», рассказал о возможности задерживать российский газ, если с 1 января 2020 г. он пойдет через Украину без контракта. Идея в том, чтобы приравнять отсутствие контракта к отсутствию правовых оснований для поставок и на этом основании «хранить газ в ПХГ» - по сути, в режиме таможенного склада, как контрабанду. 
Однако у российского газа есть конкретные потребители в Европе, и они его отбором могут оказаться весьма недовольны. Как минимум, Евросоюз может тут же открыть на полную мощность OPAL (сухопутный отвод от «Северного потока - 1»), а также дать зеленый свет достройке и полноценному запуску обходных газопроводов. Впрочем, в Киеве в любом случае рассчитывают на поддержку европейцев - в силу идеологической ангажированности ключевых политиков ЕС.

В российской интерпретации, Украина не имеет права прерывать транзит - это противоречит и Договору к Энергетической хартии 1994 г., и Соглашению об ассоциации Украины с ЕС. Киев оба документа признает, но трактует по-своему. С учетом принципа приоритетности международного права, украинское внутреннее законодательство, в том числе касающееся контрабанды, здесь вторично. По крайней мере, таков может быть один из аргументов Москвы, если Газпром решит поставлять газ для транзита без нового контракта с Киевом. Подобный опыт имеется — газ из России в Армению через Грузию в январе - феврале 2019 г. шел без контракта, стороны договорились об оплате уже постфактум.

Отдельный вопрос - сертификация нового субъекта, с которым, по идее, нужно заключать транзитный контракт. Это компания «Оператор газотранспортной системы Украины» (ОГТСУ), принадлежащая структуре под названием «Магистральные газопроводы Украины» (МГУ), которая, в свою очередь, находится под управлением министерства финансов Украины. Подобная многочленная конструкция должна формально подтверждать, что применительно к «Нафтогазу» анбандлинг [Ануфриева, c. 82] (функциональное разделение интегрированной компании по видам бизнеса) действительно произошел и оператором транзитной трубы является «независимая» компания.

Интрига в том, в какой степени ОГТСУ будет играть по правилам Евросоюза. Это зависит и от позиции руководящих органов ЕС — насколько они будут требовать трансграничного применения своих норм в отношении страны, членом Евросоюза не являющейся, но согласившейся имплементировать значительную часть энергетического права ЕС. С точки зрения теории пересечения норм международного и национального права это вопрос сложный, как и в случае с санкциями: многие компании не знают, подпадают ли они, скажем, под санкции США, если американские власти захотят их применить за пределами своей прямой юрисдикции.

Украинское национальное законодательство, куда формально имплементирован Третий энергопакет, предусматривает сертификацию нового оператора газотранспортной системы сначала национальным регулятором (Национальной комиссией, осуществляющей государственное регулирование в сферах энергетики и коммунальных услуг - НКРЭКУ), а потом секретариатом Европейского энергетического сообщества (Energy Community [Energy...]). Энергетическое сообщество создано на базе Энергетической хартии и фактически является инструментом распространения норм ЕС на соседние регионы. Украина является частью (членом) Энергетического сообщества c 2010 г. 
Национальная сертификация ОГСУ состоялась 22 ноября 2019 г., документы в секретариат Энергетического сообщества ЕС в Вене уже переданы. Министр энергетики Украины Алексей Оржель заявил, что ожидает сертификацию до 26 декабря 2019 г., а передача доли ОГТСУ в АО «Магистральные газопроводы Украины» (МГУ) должна состояться до 2 января 2020 г. При прямом применении бюрократических норм Украины заключение контракта в январе 2020 г. выходит за приемлемые рамки, поскольку действующий российско-украинский контракт на транзит газа заканчивается 1 января 2020 г. в 10 часов утра. При наличии политической воли и достижения компромисса на уровне президентов стран, однако, бюрократические преграды вполне можно преодолеть.

Кроме того, если Еврокомиссия захочет полноценно применить Третий энергопакет в транснациональной логике, то сертифицировать ОГТСУ должно не только Энергетическое сообщество, но еще и Европейская сеть операторов систем передачи газа (European Network of Transmission System Operators for Gas - ENTSOG [ENTSOG...]), то есть объединение операторов европейских газотранспортных систем. Создание ENTSOG было связано с процессом имплементации норм Третьего энергопакета в национальное законодательство стран ЕС. У этой структуры даже есть свой денежный фонд для помощи сертифицированным ею операторам, если они столкнутся с авариями. То есть сертификация в ENTSOG, которой фактически приходится отвечать деньгами за свое решение, - это не пустой звук.

Впрочем, Украина не член ЕС, хоть она через свой внутренний Закон о рынке природного газа и приняла (в возможной для нечлена ЕС степени) нормы Третьего энергопакета. Поэтому вопрос, чем в итоге удовлетворится Еврокомиссия, как она будет трактовать доктрину транснациональности в праве ЕС, остается открытым. Скорее всего, чтобы не подыгрывать Газпрому, Еврокомиссия решит, что для ОГТСУ достаточно «оперативной» сертификации в Энергетическом сообществе - а ее действительно можно сделать относительно быстро. По крайней мере, эта процедура не требует нескольких месяцев, как было бы в случае с сертификацией в ENTSOG.

Интересно, что во время пребывания в Киеве в октябре 2019 г. директор Энергетического сообщества Януш Копач, в целом лояльный курсу на поддержку Украины, признал: «На 1 января [2020 г.] может не быть независимого регулятора [украинской ГТС]. Общая задача украинских стейкхолдеров, секретариата, комиссии и международных партнеров - решить вопрос, каким же образом будет создан орган, который формально будет под правительством, но будет заявлен как независимый. Решение о сертификации оператора ПТ не независимым оператором не будет признано, особенно российской стороной» [Подготовка Украины...].

Следующая проблема - сроки проведения аукционов на бронирование мощности (процедура open season, «открытой заявки»). По нормам EC, эта процедура занимает два месяца, то есть в случае сертификации ОГТСУ Энергетическим сообществом в конце декабря 2019 г. аукцион сможет состояться лишь в конце февраля 2020 г. 
ОГТСУ - если эта новая структура действительно будет работать по правилам ЕС должен разработать условия для потенциальных заказчиков, желающих забронировать мощности газотранспортной системы Украины, и провести аукцион. Если клиентов, например, Газпром, условия не устраивают, они просто не приходят на аукцион. Тогда ОГТСУ, в принципе, должен объявить новый аукцион. При этом кроме Газпрома на этот аукцион прийти некому. Но именно таковы правила регулирования газовой инфраструктуры ЕС и стран, заимствующих нормы ЕС, в верности которым клянется Киев. Если в итоге контракт будет заключен вне этих правил, то этот факт вновь докажет ограниченность потенциала европейской интеграции как политического инструмента и весьма ограниченную эффективность ссылок на нормы ЕС игроками вне ЕС.

Газпром в связи с указанными неизбежными задержками в проведении аукционов на бронирование мощности предлагает украинской стороне пока продлить действующий транзитный договор. Предварительно возможно подписать и контракт на будущее с «отложенным стартом», указав в тексте, что он вступит в силу, когда пройдет процедура open season. Но Киев уверяет, что «Нафтогаз» не имеет права подписывать соглашение о продлении действующего контракта как раз из-за анбандлинга.

В реальности нормы ЕС можно трактовать по-разному - сама Еврокомиссия это неоднократно показывала. Нормы права России и Украины, при необходимости, тем более изменить нетрудно. Проблема только в заключении политического соглашения. И здесь открывается окно возможностей для В. Зеленского, который 25 ноября 2019 г. сам позвонил В. Путину, чтобы обсудить газовые проблемы. Но на нового украинского президента тут же напали сторонники «жесткой линии». Если В. Зеленский решится уволить в скором времени старую команду «Нафтогаза» в лице А. Коболева и Ю. Витренко (которые в ином случае будут вести борьбу с Газпромом до конца - им не нужен транзит газа, им нужны премии и сохранение базовой лояльности США), то он вполне может достичь соглашения с Москвой. Но тогда ему нужно готовиться к вероятным обвинениям в «зраде» (предательстве). Сторонники жесткой антироссийской линии в Киеве и так постоянно пытаются «подставить» Зеленского, доходя порой до карикатурных сюжетов (утверждая, например, что он принял ранее задержанные Россией и затем возвращенные ею украинские корабли «без унитазов»).

Тот факт, что В. Путин после телефонного разговора с В. Зеленским вызвал к себе сразу и министра энергетики А. Новака и руководителя Газпрома А. Миллера (и что об этом сообщили российские государственные СМИ), очень показателен. Москва явно сочла, что с Зеленским и членами его команды (например, тем же министром энергетики Алексеем Оржелем) можно договориться. Сигналы готовности к компромиссу, пускай и слабые, наблюдались и со стороны Киева. Так, Россия и Украина в начале декабря 2019 г. заключили 10-летний договор по транзиту нефти. А в Киеве был уволен глава «Энергоатома» Украины Ю. Недашковский, занимавший этот пост с марта 2014 г. и известный тем, что у него в рабочем кабинете висел портрет С. Бандеры. В итоге, после еще нескольких раундов переговоров, 20 декабря 2019 г. вице-премьер РФ Д. Козак даже сказал, что обсуждается возможность скорого подписания уже пятилетнего транзитного контракта. 
Новый транзитный контракт на несколько лет действительно может стать реальностью где-то на рубеже 2019/2020 гг. В значительной степени это устраивает все стороны. Украина продолжает получать деньги за транзит и не рискует стабильностью газового снабжения своих потребителей в зимние месяцы. Россия получает передышку и время для достройки и запуска обходных газопроводов. Европейские потребители также снижают уровень рисков для себя. Но глобально риски не сняты - украинский транзит является заложником динамики отношений Москвы и Киева, причем Киев продолжает официально называть РФ «страной-агрессором», что ставит под дамоклов меч любые экономические контракты, и газовые в том числе. К тому же Россия все равно будет постепенно снижать объем прокачки газа через Украину, и Киеву это не понравится, что вновь неизбежно актуализирует риски эскалации межстранового конфликта и прерывания транзита.

\section{Литература}

Ануфриева А.А. Регулирование иностранных инвестиций в ЕС. Общие вопросы и инвестирование в энергетический сектор. М. 2014. С. 82.

Европейская интеграция: учебник для вузов / Под ред. О.В. Буториной, Н.Ю. Кавешникова. М. 2018. С. 318.

Митрахович С. Взаимная выгода // Известия. 23.05.2018. - URL: iz.ru/746488/stanislavmitrakhovich/vzaimnaia-vygoda (дата обращения: 25.11.2019).

Подготовка Украины к сертификации оператора ГТС выполнена на 90\%, но осталось решить ряд важных задач - Копач // ЭнергоРеформа. 09.10.2019. - URL: reform.energy/news/ podgotovka-ukrainy-k-sertifikatsii-operatora-gts-vypolnena-na-90-no-ostalos-reshit-ryadvazhnykh-zadach-kopach-12670 (дата обращения: 25.11.2019).

Energy Community. Official website. — URL: energy-community.org/ (date of access: 25.11.2019). ENTSOG. Official website. — URL: entsog.eu/ (date of access: 25.11.2019). 